\title{
A note on a multi-period profit maximizing model for retail supply chain management
}

\author{
Wilco van den Heuvel and Albert P.M. Wagelmans
}

\begin{tabular}{|l|l|}
\hline \multicolumn{2}{|l|}{ ERIM REPORT SERIES RESEARCH IN MANAGEMENT } \\
\hline ERIM Report Series reference number & ERS-2003-072-LIS \\
\hline Publication & 2003 \\
\hline Number of pages & 7 \\
\hline Email address corresponding author & wvandenheuvel@few.eur.nl \\
\hline Address & Erasmus Research Institute of Management (ERIM) \\
& Rotterdam School of Management / Faculteit Bedrijfskunde \\
& Rotterdam School of Economics / Faculteit \\
& Economische Wetenschappen \\
& Erasmus Universiteit Rotterdam \\
& P.O. Box 1738 \\
& 3000 DR Rotterdam, The Netherlands \\
& Phone: +31 10 408 1182 \\
& Fax: +31 10 408 9640 \\
& Email: info@erim.eur.nl \\
& Internet: www.erim.eur.nl \\
\hline
\end{tabular}

Bibliographic data and classifications of all the ERIM reports are also available on the ERIM website: www.erim.eur.nl 


\title{
ERASMUS RESEARCH INSTITUTE OF MANAGEMENT
}

\author{
REPORT SERIES \\ RESEARCH IN MANAGEMENT
}

\begin{tabular}{|c|c|c|}
\hline \multicolumn{3}{|c|}{ BIBLIOGRAPHIC DATA AND CLASSIFICATIONS } \\
\hline Abstract & \multicolumn{2}{|c|}{$\begin{array}{l}\text { In this note we present an efficient exact algorithm to solve the joint pricing and inventory } \\
\text { problem for which Bhattacharjee and Ramesh (2000) proposed two heuristics. Our algorithm } \\
\text { appears to be superior also in terms of computation time. Furthermore, we point out several } \\
\text { mistakes in the paper by Bhattacharjee and Ramesh. }\end{array}$} \\
\hline \multirow{3}{*}{$\begin{array}{l}\text { Library of Congress } \\
\text { Classification } \\
\text { (LCC) }\end{array}$} & 5001-6182 & Business \\
\hline & 5201-5982 & Business Science \\
\hline & HF5416.5 & Pricing \\
\hline \multirow{3}{*}{$\begin{array}{l}\text { Journal of Economic } \\
\text { Literature } \\
\text { (JEL) }\end{array}$} & M & Business Administration and Business Economics \\
\hline & $\begin{array}{l}\text { M } 11 \\
\text { R } 4\end{array}$ & $\begin{array}{l}\text { Production Management } \\
\text { Transportation Systems }\end{array}$ \\
\hline & L 11 & Production, pricing, ... \\
\hline \multirow{3}{*}{$\begin{array}{l}\text { European Business Schools } \\
\text { Library Group } \\
\text { (EBSLG) }\end{array}$} & $85 \mathrm{~A}$ & Business General \\
\hline & $\begin{array}{l}260 \mathrm{~K} \\
240 \mathrm{~B}\end{array}$ & $\begin{array}{l}\text { Logistics } \\
\text { Information Systems Management }\end{array}$ \\
\hline & $160 \mathrm{~B}$ & Pricing \\
\hline \multicolumn{3}{|c|}{ Gemeenschappelijke Onderwerpsontsluiting (GOO) } \\
\hline \multirow[t]{3}{*}{ Classification GOO } & 85.00 & Bedrijfskunde, Organisatiekunde: algemeen \\
\hline & $\begin{array}{l}85.34 \\
85.20\end{array}$ & $\begin{array}{l}\text { Logistiek management } \\
\text { Bestuurlijke informatie, informatieverzorging }\end{array}$ \\
\hline & 83.11 & Micro-economie \\
\hline \multirow[t]{3}{*}{ Keywords GOO } & \multicolumn{2}{|c|}{ Bedrijfskunde / Bedrijfseconomie } \\
\hline & \multicolumn{2}{|c|}{ Bedrijfsprocessen, logistiek, management informatiesystemen } \\
\hline & \multicolumn{2}{|c|}{ Voorraden, prijsbeleid, wiskundige programmering } \\
\hline Free keywords & \multicolumn{2}{|c|}{ Inventory, Pricing, Dynamic programming } \\
\hline
\end{tabular}




\title{
A note on a multi-period profit maximizing model for retail supply chain management
}

\author{
Wilco van den $\operatorname{Heuvel}^{a *}$, Albert P.M. Wagelmans ${ }^{a \dagger}$ \\ ${ }^{a}$ Faculty of Economics, Erasmus University Rotterdam, Econometric Institute, \\ P.O. Box 1738, 3000 DR Rotterdam, The Netherlands
}

\begin{abstract}
In this note we present an efficient exact algorithm to solve the joint pricing and inventory problem for which Bhattacharjee and Ramesh (2000) proposed two heuristics. Our algorithm appears to be superior also in terms of computation time. Furthermore, we point out several mistakes in the paper by Bhattacharjee and Ramesh.
\end{abstract}

Keywords: Inventory; Pricing; Dynamic programming

\section{Introduction}

In a recent paper Bhattacharjee and Ramesh (2000) consider a joint pricing and inventory model for a monopolistic retailer who is dealing in a single product. For a given planning horizon the retailer wants to maximize his profit considering revenue and all relevant costs. Bhattacharjee and Ramesh propose two heuristic algorithms to solve this problem. In this note we show that the problem can be solved to optimality in an efficient way. We do this by applying a method already proposed by Thomas (1970) for a similar problem. Furthermore, we point out some mistakes in the paper of Bhattacharjee and Ramesh.

The remainder of this note is organized as follows. In section 2 we describe the joint pricing and inventory model and we give a mathematical formulation. In section 3 we give the main results presented by Bhattacharjee and Ramesh (2000) and we point out some mistakes. In section 4 we present the exact method proposed by Thomas (1970) and we apply this method to the Bhattacharjee and Ramesh case.

\footnotetext{
*Corresponding author. Tel.: +31-10-4081321, Email: wvandenheuvel@few.eur.nl

†Email: wagelmans@few.eur.nl
} 


\section{Problem description}

Bhattacharjee and Ramesh (2000) consider the following joint pricing and inventory model. There is a monopolistic retailer dealing in a single product over a finite time horizon. At the beginning of each period ordering and pricing decisions are made. This means that in each period a different price can be set. For each order made by the retailer there is a fixed ordering cost and variable purchasing cost. Holding cost is incurred for carrying inventory from a period to the next period.

Furthermore, it is assumed in the paper that demand satisfies the following equation

$$
d(p)=\beta p^{-\alpha},
$$

where $\beta$ is a constant, $p$ is the price and $\alpha>1$ is the demand elasticity. Finally, it is assumed that price in each period $t$ satisfies $p_{\min } \leq p_{t} \leq p_{\max }$. We will assume that all demand has to be satisfied, i.e., loss of demand is not allowed. Before giving the mathematical formulation, we note that the mathematical programming formulation of this problem presented in Bhattacharjee and Ramesh (2000) is incorrect. This can be seen by taking $q_{t}=0$ for all periods, which is always optimal in their formulation (see p. 588 formula (2.2)-(2.6)).

Using the following notation,

$$
\begin{aligned}
T & =\text { model horizon } \\
K & =\text { fixed ordering cost } \\
c & =\text { per unit purchase cost } \\
h & =\text { holding costs per unit per period } \\
q_{t} & =\text { ordered quantity in period } t \\
I_{t} & =\text { ending inventory in period } t
\end{aligned}
$$

the problem can be formulated as follows

$$
\begin{array}{ll}
\max & \sum_{t=1}^{T} d\left(p_{t}\right) p_{t}-C(D(p)) \\
\text { s.t. } & p_{\text {min }} \leq p_{t} \leq p_{\max } \quad t=1, \ldots, T
\end{array}
$$

where

$$
\begin{array}{rlr}
C(D(p))=\min & \sum_{t=1}^{T} K \delta\left(q_{t}\right)+c q_{t}+h I_{t} & \\
\text { s.t. } & I_{t}=I_{t-1}-d\left(p_{t}\right)+q_{t} & t=1, \ldots, T \\
& q_{t}, I_{t} \geq 0 & t=1, \ldots, T \\
& I_{0}=0 &
\end{array}
$$

with

$$
\delta(x)= \begin{cases}0 & \text { for } x=0 \\ 1 & \text { for } x>0 .\end{cases}
$$

and $D(p)$ is the demand vector, i.e., $D(p)=\left[d\left(p_{1}\right), \ldots, d\left(p_{T}\right)\right]$. 
In problem (2) we maximize the total revenue minus total cost over all periods, such that price is bounded from above and below. If we set $p_{\min }=0$ and $p_{\max }=\infty$, then price is not restricted in the model. The total cost is represented by $C(D(p))$, which is a 'standard' Wagner-Whitin problem (see Wagner and Whitin (1958)). We minimize ordering, purchasing and holding cost, such that demand is satisfied and order quantity and ending inventory are non-negative in each period. Furthermore, we may assume without loss of generality that starting inventory is zero.

\section{Main results presented in Bhattacharjee and Ramesh (2000)}

We first discuss two claims by Bhattacharjee and Ramesh that are false.

Bhattacharjee and Ramesh claim that for a profit-maximizing firm it is always profitable to meet total demand. This means that shortage cost can be ignored and only the model with no loss of demand needs to be considered. In the proof of this results the authors use the fact that by increasing price in case of a shortage, there is an increase in revenue and a saving in shortage cost. However, later they assume that $p_{\min } \leq p_{t} \leq p_{\max }$. This is in contradiction with the proof where it is assumed that price can always be increased. In the following 1-period example we show that it can be optimal to have loss of demand.

Example 1 Consider a 1-period problem with $K=0$ and with $c-s>p_{\max }$, where $s>0$ is the shortage cost per item. The total profit can be found by

$$
\begin{array}{ll}
\max & (p-c) \min \{q, d(p)\}-s \max \{0, d(p)-q\} \\
\text { s.t. } & q \geq 0 \\
& p_{\text {min }} \leq p \leq p_{\text {max }}
\end{array}
$$

Rewriting (3) we have

$$
\begin{array}{ll}
\max & (p-c+s) \min \{q, d(p)\}-s d(p) \\
\text { s.t. } & q \geq 0 \\
& p_{\min } \leq p \leq p_{\max } .
\end{array}
$$

Because of the assumption, we have that $p-c+s<0$ and because $d(p)$ is decreasing, it follows immediately from (4) that it is optimal to set $q=0$ and $p=p_{\max }$. So in this example it is optimal to have loss of demand.

Furthermore, Bhattacharjee and Ramesh claim that the maximum profit function for a single period in a subplan is concave. In the next section, however, we will prove that the maximum profit function for a single period has a shape as shown in figure 1, i.e., the function is not concave on the whole interval, but it is convex for $p>\widehat{p}$.

Bhattacharjee and Ramesh propose two heuristic algorithms (algorithm I and II) to solve the problem. To justify the application of heuristics, they refer to the exponential nature of the 


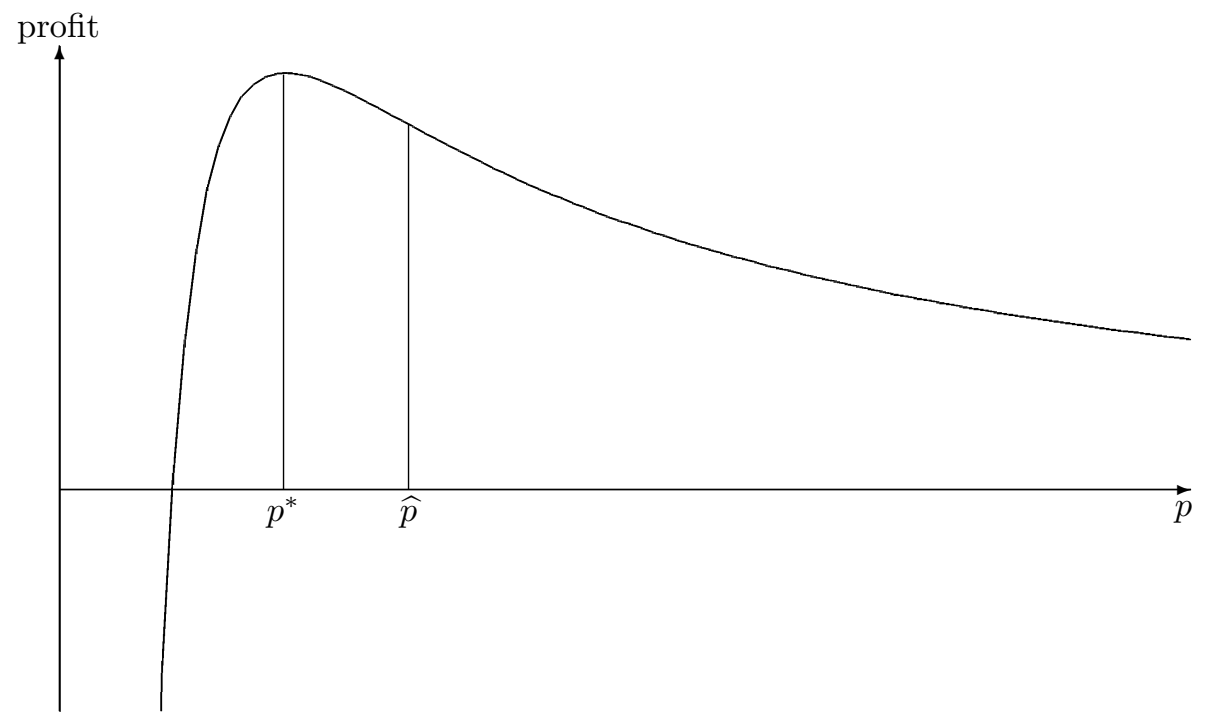

Figure 1: maximum profit function for a single period of a subplan

problem and the characteristics of the maximum profit function. Indeed there are $2^{T-1}$ possible ordering policies (assuming positive demand in period 1), but this is also the case in the classical Wagner-Whitin problem (see Wagner and Whitin (1958)) which can be solved in polynomial time. Moreover, in both heuristics there is a predetermined value $r$, which defines the maximum length of a subplan to be considered. For such a subplan all $\left(2^{r-1}\right)$ ordering policies are generated, which means that the heuristics have a running time which is exponential in $r$. Furthermore, this also means that the heuristics may perform poorly if the optimal size of a subplan is larger than $r$. To determine the performance of their heuristics, Bhattacharjee and Ramesh (2000) used complete enumeration to calculate optimal values for some 5 -period and 10-period problems. The worst case deviation from optimality of algorithm I was more than 28\%. Algorithm II performed somewhat better with a worst case deviation of more than $18 \%$, which is still quite large.

In the next section we will show that the problem can be solved to optimality in polynomial time.

\section{Exact algorithm}

\subsection{The algorithm}

In this section we propose an exact algorithm that has a running time which is quadratic in the model horizon $T$. This method was proposed by Thomas (1970) for a similar problem. Thomas considers a more general problem, where the demand functions and the cost parameters may vary over time. The proposed method (in the general case) is explained below. Note that Thomas 
presented the model as a minimization problem, whereas we present it as a maximization model.

Define $p_{j t}$ as the price vector $p_{j t}=\left[p_{j}, \ldots, p_{t}\right]$ and define $\pi_{j t}\left(p_{j t}\right)$ as the total profit if production takes place in period $j$ for periods $j, \ldots, t$ (we will call this a subplan), i.e.,

$$
\pi_{j t}\left(p_{j t}\right)=\sum_{k=j}^{t}\left[p_{k}-c_{k}-\sum_{i=j}^{k-1} h_{i}\right] d_{k}\left(p_{k}\right)-K_{j}
$$

Furthermore, we define $\pi_{j t}$ as the maximum profit for a subplan consisting of periods $j, \ldots, t$, i.e.,

$$
\pi_{j t}=\max _{p_{j t}} \pi_{j t}\left(p_{j t}\right) .
$$

Thomas (1970) shows that if a setup takes place in period $r$ and the next setup in period $s$, then the optimal price for period $t=r, \ldots, s-1$ must be set at the value which maximizes

$$
\left(p_{t}-c_{r}-\sum_{j=r}^{t-1} h_{j}\right) d_{t}\left(p_{t}\right) .
$$

Dependent on the structure of $d_{t}\left(p_{t}\right)$ we can calculate this optimal price in an analytical way or, if necessary, by enumeration. Substituting the optimal prices in (5) we are able to determine $\pi_{j t}$. Then the following forward recursion enables us to find the optimal profit for the whole model horizon:

$$
F(t)=\max _{j=1, \ldots, t}\left(F(j-1)+\pi_{j t}\right) \text { for } t=1, \ldots, T \text { with } F(0)=0
$$

\subsection{Application to the Bhattacharjee and Ramesh case}

For the Bhattacharjee and Ramesh case we can find the optimum of (5) in an analytical way. Substituting demand function (1) and the constant cost parameters in (5) we have that

$$
\pi_{j t}\left(p_{j t}\right)=\sum_{k=j}^{t}\left[p_{k}-c-\sum_{i=j}^{k-1} h\right] \beta p_{k}{ }^{-\alpha}-K=\sum_{k=j}^{t}\left[p_{k}-c-(k-j) h\right] \beta p_{k}{ }^{-\alpha}-K .
$$

Calculating the first order conditions we have for $i=j, \ldots, t$

$$
\frac{\partial \pi_{j t}\left(p_{j t}\right)}{\partial p_{i}}=0 \Longleftrightarrow \alpha \beta c p_{i}{ }^{-\alpha-1}+(i-j) h \alpha \beta p_{i}{ }^{-\alpha-1}-(\alpha-1) \beta p_{i}{ }^{-\alpha}=0
$$

or

$$
p_{i}^{*}=\frac{\alpha(c+(i-j) h)}{\alpha-1}>0 .
$$

Note that $p_{i}^{*}$ does not depend on $p_{k}$ for $k \neq i$, so that the optimal price for each period can be determined independently. Furthermore, note that $p_{i}^{*}$ does not depend on $t$, which implies that the optimal price for a single period is independent of the length of a subplan. Finally, it is easy to verify that

$$
\left.\frac{\partial \pi_{j t}\left(p_{j t}\right)}{\partial p_{i}}\right|_{p_{i}}>0 \text { for } p_{i}<p_{i}^{*} \text { and }\left.\frac{\partial \pi_{j t}\left(p_{j t}\right)}{\partial p_{i}}\right|_{p_{i}}<0 \text { for } p_{i}>p_{i}^{*}
$$


which implies that the maximum profit function for a single period in a subplan is unimodal and that it has a unique optimum at price $p_{i}^{*}$.

If we analyze the second order partial derivative we find

$$
\frac{\partial^{2} \pi_{j t}\left(p_{j t}\right)}{\partial p_{i}{ }^{2}}=-\alpha(\alpha+1) \beta(c+(i-j) h) p_{i}{ }^{-\alpha-2}+\alpha(\alpha-1) \beta p_{i}{ }^{-\alpha-1},
$$

which is equal to zero for

$$
\widehat{p}_{i}=\frac{(\alpha+1)(c+(i-j) h)}{\alpha-1}>p_{i}^{*}
$$

It is not difficult to verify that the second order partial derivative is smaller than zero for $p_{i}<\widehat{p_{i}}$ and larger than zero for $p_{i}>\widehat{p_{i}}$. This means that the maximum profit function for a single period in a subplan is concave for $p_{i}<\widehat{p_{i}}$ and convex for $p_{i}>\widehat{p_{i}}$. This shows that the claim made in Bhattacharjee and Ramesh (2000) about the concavity of the maximum profit function is incorrect.

Because Bhattacharjee and Ramesh assume a constant demand function and constant cost parameters, it follows from (5), (6) and (9) that

$$
\pi_{j t}=\pi_{1, t-j+1} \text { for all } 1 \leq j \leq t \leq T .
$$

This means that it is only necessary to evaluate $\pi_{1 t}$ for $t=1, \ldots, T$. If we define

$$
\widetilde{p}_{t}=\frac{\alpha(c+(t-1) h)}{\alpha-1},
$$

then we can use recursion formulas (11) and (12) to calculate $\pi_{1 t}$ for $t=1, \ldots, T$ in linear time:

$$
\begin{gathered}
\widetilde{p}_{t+1}=\widetilde{p}_{t}+\frac{\alpha h}{\alpha-1} \\
\pi_{1, t+1}=\pi_{1, t}+\left(\widetilde{p}_{t+1}-c-t h\right) \beta \widetilde{p}_{t+1}^{-\alpha}
\end{gathered}
$$

with

$$
\widetilde{p}_{1}=\frac{\alpha c}{\alpha-1} \text { and } \pi_{11}=\left(\widetilde{p}_{1}-c\right) \beta \widetilde{p}_{1}^{-\alpha}-K .
$$

By applying recursion formula (7) and using (10) we can find the optimal total profit. The optimal prices can be found by using formula (9).

Because $F(t)$ can be determined in $\mathrm{O}(t)$ time for a fixed $t$, it takes $\mathrm{O}\left(T^{2}\right)$ time to evaluate $F(T)$. So the method proposed by Thomas (1970) is better than the heuristics proposed by Bhattacharjee and Ramesh in two ways. First, it is an exact algorithm instead of a heuristic. Second, the method appears to require a much lower running time. We implemented the algorithm in $\mathrm{C}++$ and it took less than a second to solve a 1000-period problem instance, whereas Bhattacharjee and Ramesh only report results for their heuristics for problem instances with a maximum of 15 periods. Note that Thomas (1970) proved a planning horizon theorem that can be used to further speed up computations.

We note that the above method does not take into account the restriction $p_{\min } \leq p_{t} \leq p_{\max }$. However, this restriction does not make the problem harder to solve. Including this restriction, 
the price that maximizes (8) for each period $i$ must be equal to $p_{\min }, p_{\max }$ or $p_{i}^{*}$. This means that we have a constant number of possible optimal prices. So the (theoretical) running time of the algorithm is not affected by this restriction.

Finally, Bhattacharjee and Ramesh (2000) also consider the case of perishable goods. They assume that the goods may perish after a fixed number of periods, say $m$. It is also easy to extend Thomas' method with this additional feature. Clearly, it is never optimal to order for more than $m$ periods, because this will lead to unnecessary purchasing and holding cost. So for finding $F(t)$ in (7) we do not need to consider the term $F(j-1)+\pi_{j t}$ for all $j=1, \ldots, t$, but only for $j=\max \{1, t-m+1\}, \ldots, t$. It is easy to verify that the running time of the algorithm is reduced to $\mathrm{O}(m T)$ in the case of perishable goods.

\section{References}

S. Bhattacharjee and R. Ramesh, 2000. A multi-period profit maximizing model for retail supply chain management: An integration of demand and supply-side mechanisms, European Journal of Operational Research, 122 (3) 584-601.

J. Thomas, 2000. Price production decisions with deterministic demand, Management Science, 16 (11) $747-750$.

H.M. Wagner and T.M. Whitin, 1958. Dynamic version of the economic lot size model, Management Science, 5 (1) 89-96. 


\section{Publications in the Report Series Research* in Management}

ERIM Research Program: "Business Processes, Logistics and Information Systems"

2003

Project Selection Directed By Intellectual Capital Scorecards

Hennie Daniels and Bram de Jonge

ERS-2003-001-LIS

http://hdl.handle.net/1765/265

Combining expert knowledge and databases for risk management

Hennie Daniels and Han van Dissel

ERS-2003-002-LIS

http://hdl.handle.net/1765/266

Recursive Approximation of the High Dimensional max Function

Ş. II. Birbil, S.-C. Fang, J.B.G. Frenk and S. Zhang

ERS-2003-003-LIS

http://hdl.handle.net/1765/267

Auctioning Bulk Mobile Messages

S.Meij, L-F.Pau, E.van Heck

ERS-2003-006-LIS

http://hdl.handle.net/1765/274

Induction of Ordinal Decision Trees: An MCDA Approach

Jan C. Bioch, Viara Popova

ERS-2003-008-LIS

http://hdl.handle.net/1765/271

A New Dantzig-Wolfe Reformulation And Branch-And-Price Algorithm For The Capacitated Lot Sizing Problem With Set Up Times

Zeger Degraeve, Raf Jans

ERS-2003-010-LIS

http://hdl.handle.net/1765/275

Reverse Logistics - a review of case studies

Marisa P. de Brito, Rommert Dekker, Simme D.P. Flapper

ERS-2003-012-LIS

http://hdl.handle.net/1765/277

Product Return Handling: decision-making and quantitative support

Marisa P. de Brito, M. (René) B. M. de Koster

ERS-2003-013-LIS

http://hdl.handle.net/1765/278

\footnotetext{
A complete overview of the ERIM Report Series Research in Management: $\underline{\text { http://www.erim.eur.nl }}$

ERIM Research Programs:

LIS Business Processes, Logistics and Information Systems

ORG Organizing for Performance

MKT Marketing

F\&A Finance and Accounting

STR Strategy and Entrepreneurship
} 
Managing Product Returns: The Role of Forecasting

Beril Toktay, Erwin A. van der Laan, Marisa P. de Brito

ERS-2003-023-LIS

http://hdl.handle.net/1765/316

Improved Lower Bounds For The Capacitated Lot Sizing Problem With Set Up Times

Zeger Degraeve, Raf Jans

ERS-2003-026-LIS

http://hdl.handle.net/1765/326

In Chains? Automotive Suppliers and Their Product Development Activities

Fredrik von Corswant, Finn Wynstra, Martin Wetzels

ERS-2003-027-LIS

http://hdl.handle.net/1765/363

Mathematical models for planning support

Leo G. Kroon, Rob A. Zuidwijk

ERS-2003-032-LIS

http://hdl.handle.net/1765/332

How and why communications industry suppliers get "squeezed out" now, and the next phase

L-F Pau

ERS-2003-033-LIS

http://hdl.handle.net/1765/317

Financial Markets Analysis by Probabilistic Fuzzy Modelling

Jan van den Berg, Uzay Kaymak, Willem-Max van den Bergh

ERS-2003-036-LIS

http://hdl.handle.net/1765/323

WLAN Hot Spot services for the automotive and oil industries :a business analysis or : "Refuel the car with petrol and information , both ways at the gas station "

L-F Pau, M.H.P.Oremus

ERS-2003-039-LIS

http://hdl.handle.net/1765/318

A Lotting Method for Electronic Reverse Auctions

U. Kaymak, J.P. Verkade and H.A.B. te Braake

ERS-2003-042-LIS

http://hdl.handle.net/1765/337

Supply Chain Optimisation in Animal Husbandry

J.M. Bloemhof, C.M. Smeets, J.A.E.E. van Nunen

ERS-2003-043-LIS

http://hdl.handle.net/1765/353

A Framework for Reverse Logistics

Marisa P. de Brito and Rommert Dekker

ERS-2003-045-LIS

http://hdl.handle.net/1765/354

An assessment system for rating scientific journals in the field of ergonomics and human factors Jan Dul and Waldemar Karwowski

ERS-2003-048-LIS

http://hdl.handle.net/1765/432 
Circulation of Railway Rolling Stock: A Branch-and-Price Approach

Marc Peeters and Leo Kroon

ERS-2003-055-LIS

http://hdl.handle.net/1765/902

Emerging Multiple Issue e-Auctions

Jeffrey E. Teich, Hannele Wallenius, Jyrki Wallenius and Otto R. Koppius

ERS-2003-058-LIS

http://hdl.handle.net/1765/922

Inventory Management with product returns: the value of information

Marisa P. de Brito and E. A. van der Laan

ERS-2003-060-LIS

http://hdl.handle.net/1765/925

Promising Areas for Future Research on Reverse Logistics: an exploratory study

Marisa P. de Brito

ERS-2003-061-LIS

http://hdl.handle.net/1765/926

A Polynomial Time Algorithm for a Deterministis Joint Pricing and Inventory Model

Wilco van den Heuvel and Albert P.M. Wagelmans

ERS-2003-065-LIS

http://hdl.handle.net/1765/929

A geometric algorithm to solve the ni/g/ni/nd capacitated lot-sizing problem in o( $\left.t^{2}\right)$ time Wilco van den Heuvel and Albert P.M. Wagelmans

ERS-2003-066-LIS

http://hdl.handle.net/1765/930

Arrival Processes for Vessels in a Port Simulation

Eelco van Asperen, Rommert Dekker, Mark Polman, Henk de Swaan Arons \& Ludo Waltman ERS-2003-067-LIS

http://hdl.handle.net/1765/973

The distribution-free newsboy problem with resalable returns

Julien Mostard, Rene de Koster and Ruud Teunter

ERS-2003-068-LIS

http://hdl.handle.net/1765/975 